\title{
University-Industry Technology Transfer in India: a Plausible Model Based on Success Stories from the USA, Japan, and Israel
}

\author{
Ramya Ravi ${ }^{1} \cdot$ Manthan D. Janodia ${ }^{2}$ (D)
}

Received: 9 May 2021 / Accepted: 12 January 2022 / Published online: 3 February 2022

(c) The Author(s) 2022

\begin{abstract}
Patenting and technology commercialization activities are rapidly gaining momentum in Indian academia. Currently, there is paucity of data suggesting technology commercialization activities among Indian academia. This study aims to examine issues regarding technology commercialization among Indian academics. The objectives of this study are to (1) understand the policy implications of universityindustry technology transfer and (2) propose a conceptual model for technology transfer suitable for Indian scenario. The data included for our analysis is drawn from our previous study of 25 Indian Universities. The orientation of the paper is as follows: "Literature Review" is subdivided into two sub-sections - "Policies Implemented for Leveraging Successful Academic Research Commercialization in the USA, Japan, and Israel" and "University Research Commercialization - Case Studies of Universities in the USA, Japan, and Israel" are presented. "Methodology" deals with the methodology used for the study. "Discussion" is further subdivided into three sections — "Analysis and Comparisons of Policy Implications on University-Industry Technology Transfer," "Practice of Academic Technology Transfer in Indian Universities/Institutes," and "Conceptual Model Recommended for University-Industry Tech Commercialization in India." "Conclusion" concludes the topic. The current practices of academia-industry knowledge commercialization in India are limited, and the paper is an attempt to propose a suitable model to encourage commercialization activities by Indian universities.
\end{abstract}

Keywords Indian university-industry technology transfer $\cdot$ Knowledge commercialization - Academic-industry collaboration · Technology transfer models · Policies for academic research collaborations

Manthan D. Janodia

manthan.j@manipal.edu; manthan.janodia@gmail.com

1 Department of Pharmaceutical Quality Assurance, Manipal College of Pharmaceutical Sciences, Manipal Academy of Higher Education, Manipal 576104, Karnataka, India

2 Department of Pharmacy Management, Manipal College of Pharmaceutical Sciences, Manipal Academy of Higher Education, Manipal 576104, Karnataka, India 


\section{Introduction}

The process of transforming innovations protected through Intellectual Property Rights (IPR) into products marketable is called technology transfer. Universityindustry technology transfer refers to the activities relating to the transfer of academic research findings to the industrial sector (Technology transfer in countries in transition: policy and recommendations, n.d.). To facilitate technology transfer, government policies play a vital role in promoting the research and economic competence of the nation (King \& Nowack, 2003). The university-industry technology commercialization in the USA had a new beginning post the implementation of The Bayh-Dole Act 1980 which led to the rapid growth of industries. One of the objectives of the Bayh-Dole Act 1980 was to promote investment from the private sector into the commercialization of federally funded research for societal benefit. The licensing survey of FY96 by the Association of University Technology Managers (AUTM) reported that the commercialization of discoveries originating from academic research organizations to the companies played a predominant role in the growth of the US economy (Berneman \& Denis, 1998). Similarly, Japan's university system was established in the final quarter of the twentieth century. In 1971, the Council of Science and Technology of Japan framed fundamental policies on encouraging the linkages between university researchers, national research institutes, and private research laboratories. In 1977, the Ministry of Education of Japan gradually reduced the restrictions on industrial support for $R \& D$ in national universities, thus promoting new forms of cooperative research. The first such cooperative research came up in 1983, which was named Monbusho's cooperative research program that opened the gates for university industry collaborations (Collins \& Wakoh, 2000). The Law of Special Measures to Revive Industry 1999 (Japanese Bayh Dole Act) revolutionized the concept of university research commercialization in Japan by successfully increasing the number of patent applications filed by universities and conceptualized technology transfer to Japanese industries (Takenaka, 2005). Similarly, Israel has remarkable achievement in encouraging the commercialization of university research and technology transfer. In Israel, the concept of knowledge transfer from the universities predates intervention by the government in the form of incentive programs but relies on university bylaws. No centrally implemented policy prevails to encourage the transfer of technology or research. Moreover, there are no coordinated efforts to systemize university-industry interaction, but conventions have been strengthened by practice (Wain et al., n.d.). Some of the notable findings of AUTM report of 2020, based on the survey of nearly 200 research institutions on activities from research funding to patent and licensing, include the following: (i) research funding grew to $\$ 83.1 \mathrm{bn}$, a $7.6 \%$ increase over 2019 ; (ii) 27,112 invention disclosures are approximately $6.8 \%$ higher than the previous year; (iii) licensing options topped 10,000; and (iv) 1117 startups were formed that were directly impacting local economies (Technology Transfer Licensing Survery I AUTM, n.d.). Furthermore, some of the succesfull cases of university-industry technology transfer practices in these nations are discussed in the later sections of the paper. 
The concept of patenting and commercialization is gaining momentum in India, yet there is a need to strengthen academic commercialization both in terms of implementing national policies and stratified models to bring the research output from universities/research institutes to market for public benefit (Nandagopal, 2013).

Few studies recommend policy measures to improve university-industry technology transfer in India. The objective of this study is to (1) understand the policy implications of university-industry technology transfer and (2) propose conceptual models for technology transfer based on empirical evidence concerning various policies/models implemented in the USA, Japan, and Israel. The comparison with these developed nations is important to understand the nuts and bolts of the successful commercialization of academic research. The criterion to choose these nations is based on diversity of geographical locations and proven success stories in technology commercialization by universities. The data included for our analysis is drawn from our earlier study from 25 Indian universities (Ravi \& Janodia, 2021). The information on policies and models was obtained from published literature and official websites. The orientation of the paper is as follows: "Literature Review" is subdivided into two sub-sections — "Policies Implemented for Leveraging Successful Academic Research Commercialization in the USA, Japan, and Israel" and "University Research Commercialization - Case Studies of Universities in the USA, Japan, and Israel" are presented. "Methodology" deals with the methodology used for the study. "Discussion" is further subdivided into three sections — "Analysis and Comparisons of Policy Implications on University-Industry Technology Transfer," "Practice of Academic Technology Transfer in Indian Universities/Institutes," and "Conceptual Model Recommended for University-Industry Tech Commercialization in India." "Conclusion" concludes the topic. The current practices of academia-industry knowledge commercialization in India are limited. Based on both (i) the comparative study on policies and technology transfer models practiced in few universities of the USA, Japan, and Israel and (2) analyzing the current practices in India, the paper is an attempt to encourage academic commercialization activities by proposing a suitable model.

\section{Literature Review}

\section{Policies Implemented for Leveraging Successful Academic Research Commercialization in the USA, Japan, and Israel}

\section{United States of America}

The Bayh-Dole Act in 1980 became a game-changer in encouraging commercializing university research. Before Bayh-Dole Act 1980, the US federal government owned the patents on government-funded projects and only non-exclusive licenses were available. Moreover, during the period focus was on publications with little requirement to convert research into commercially viable products. The rationale behind the government owning the patent was that public money spent on 
the invention must be available to all. The goals of the technology transfer policy changed in 1980 with an emphasis on promoting economic development, enhancing US competitiveness through innovation, and encouraging commercialization. Several laws were implemented to achieve the policy objectives. Bayh-Dole Act 1980 emphasized on universities/non-profit organizations to retain the title of innovations developed under government-funded research projects and supported universityindustry collaborations for commercialization and inventors/researchers to attain shares on royalty generated by commercializing research. Moreover, universities were expected to apply for patents on inventions they select on their own and to give preferences for licensing to small businesses. Furthermore, from the perspective of the federal agency, the government retains the non-exclusive license to practice patents throughout the world and the universities must report back the progress to the funding agency. The preference was given to business entities who agreed to manufacture in the USA. This Act was enforced to prioritize technology transfer among federal agencies and encourage them to enter into Cooperative Research and Development Agreements (CRADAs) (Lamm, 2018). America Invents Act of 2011 changed the principle of the patent filing system in the USA from "first to invent" to "the first inventor to file." This aligned the US system with other countries (Federal Technology Transfer Act and Related Legislation, Advancing the Federal Technology Transfer Act (FTTA) US EPA, n.d.).

\section{Japan}

Before 2004, Japanese inventions arising from government grants and sponsored research were owned by the nation, usually by the Ministry of Education, Culture, Sports, Science, and Technology (MEXT). Such inventions were either free to use or would be transferred to the parties under a non-exclusive license against modest royalties, whereas in the case of contractual company-sponsored research, the company could retain an exclusive license. The inventors could own the inventions arising from donations or receive the standard allowance for research as per the policy of the concerned university. The average number of patents filed by national universities contributed to $50-70 \%$ of total applications per year. There were barriers in university-industry collaborations wherein the government employees and faculty members from national universities were barred from compensation for consultation outside the organization. Moreover, funds from sponsored research were prohibited to compensate the salaries of researchers working under the project. To address the discrepancies, the Japanese government implemented four laws in a span of 6 years from 1998 to 2004 that changed the legal framework of IP management and academia-industry collaboration. The four laws were the following. (1) Law to Promote the Transfer on University Technologies (the TLO law) in 1998 emphasized a system for the Japanese government to approve university Technology Licensing Offices (TLOs). This law endorsed transparency, arbitrated systematic transfers of academic research to industries, and channelized the compensation to inventors, laboratories, and the university. (2) Law of Special Measures to Revive Industry, in 1999 (the Japan Bayh-Dole Act), had the same strategies as the US Bayh-Dole Act, with an exception that it cannot be implemented by universities until they attained the legal status as semi-autonomous 
administrative entities in 2004. (3) The Law to Strengthen Industrial Technology supported the university researchers to establish and manage companies, which was implemented in the year 2000. It also removed barriers to using funds from sponsored research, which could be used to pay the salaries of permanent administrators and teaching staff involved in the project. (4) In April 2004, the University Incorporation Law gave national universities an independent legal status, which earlier was the branch of MEXT. By attaining the status as legally independent entities, Article 35 of Japan Patent Law could be enforced, where the employee's inventions are assigned to the employer unlike earlier when the invention was owned by MEXT (Kneller, 2011).

\section{Israel}

Israel is an innovation-driven country. The country was ranked 24th in the International Institute for Management Development (IMD) ranking in the year 2014 and was placed 27th in the World Economic Forum (WEF) global competitiveness index. Israel was also ranked 19th in the group of high human development in the year 2014 according to the United Nations Development Program's Human Development Report Index (Wonglimpiyarat, 2016). One of the reasons for the economic growth of Israel is leveraging the untapped potential for technology transfer. The commercialization of academic research in Israel is primarily driven by a few universities with established technology transfer offices such as Hebrew University (Yisum), Tel Aviv University (Ramot), Weizman Institute (Yeda), Bar Ilan University (Bar Ilan), Technion Israel Institute of Technology (Dimotech), Haifa University (Carmel), and Ben Gurion University (BGN Technology Ltd). All these universities feature among the top 500 universities globally as per the Academic Ranking of World Universities (ARWU), popularly known as Shanghai Ranking (Ravi \& Janodia, 2020). The universities are considered as "Intellectual and Economic Engines" in Israel. The Council of Higher Education (CHE) established in the year 1958 serves as Israel's guiding institution for higher education. The Planning and Budgeting Committee (PBC) in the year 1977 was established to streamline the budget allocation and approvals for Israel's Higher Education Institutes (HEIs). The government of Israel provides financial support for basic research to the universities and provides intervention programs for "bridging the gap." The universities have the freedom to decide on their policy and regulations independently and share common principles. All universities own a for-profit company known as Technology Transfer Company (TTC). TTCs handle the IP of universities and are responsible for the research commercialization policy of the university. The Govt. of Israel has implemented various programs supporting academic-industry collaborations to produce innovative products. These programs include (a) KAMIN operated by the Chief Scientist at the ministry of the economy (OCS) which supports applied research in universities, (b) NOFAR Incentive Programme to encourage academic institutions in conducting applied research in biotechnology, (c) the MAGNETON Incentive Programme which assists collaboration between academic researchers and Israeli companies leading to technology transfer, (d) the MAGNET Consortiums program, encouraging companies and research institutions to collaborate and develop innovative technologies, and (e) the HEZNEK program which is the government seed fund. It is a co-investment fund 
by the government investing in a start-up company, proportional to the investment of the investing entity. The overall success of technology transfer in Israeli universities was due to the transition from a "bottom-up" strategy to a "top-down strategy." (Messer-Yaron, 2014; Research office Legislative council Secretariate, 2017; Wonglimpiyarat, 2016).

Our earlier study findings state that research commercialization in Indian academics is in nascent stages. Academicians focus more on publishing research papers rather than focusing on commercialization of their novel findings. The study recommends that (i) Indian universities must leverage expertise in specific domains or pursue interdisciplinary research to generate revenue from knowledge commercialization, (ii) focus on the commercial viability of research, and (iii) identify mechanisms to collaborate with industrial partners (Ravi \& Janodia, 2021).

\section{University Research Commercialization - Case Studies of Universities in the USA, Japan, Israel}

\section{Stanford University}

Stanford University is considered one of the world leaders in technology transfer. Stanford University's Office of Technology Licensing (OTL) was established in 1970 and has received more than 594 mn USD in cumulative gross royalties (Page, 2008). A study analyzed the data collected from Stanford University and concluded that the revenue generated from licenses to startups was 6.4 times more than the income generated from licenses to non-startups (Axanova, 2012). The technology transfer process conceptualized at Stanford is a continuous cycle focusing on licensing the product and generating revenue to help fund research and innovation. The model adopted at Stanford includes 10 steps, which are listed in the following:

Step 1: Research - experiments during research lead to discoveries and inventions. Step 2: Invention and technology disclosure - confidential document on the details of the invention is sent to OTL that begins the formal process of technology transfer. Step 3: Assessment - OTL conducts a patent search on the invention and assesses the potential for commercialization of the invention.

Step 4: Intellectual property protection - patent filing is the next stage if appropriate, warranted, and necessary.

Step 5: Marketing - Stanford is committed to marketing all technologies to suitable companies interested in the product.

Step 6: Selecting the best licensee (s) - in the case of several parties for one invention, OTL endeavors non-exclusive license or grant field-of-use licenses.

Step 7: Licensing - OTL negotiates and executes license agreement and permit certain license in return for financial and other benefits.

Step 8: Commercialization - most of the inventions are very early stage and require further development; the licensee company makes significant investments of funds and time to commercialize the product or service. 
Step 9: Royalties — received by the university is distributed following the policy of the university.

Step 10: Reinvested - royalties shared overall in the university collectively foster further research and innovations (Office of Licensing Technology, 2012).

The OTL promotes technologies to be transferred for societal benefits while generating revenue to support research. From September 2019 to August 2020, Stanford received USD 114 million in gross royalty from 847 technologies transferred. Eighty-four of the inventions generated approximately USD 100,000. Ten inventions generated USD $1 \mathrm{mn}$ or more. Of 594 invention disclosures submitted, 121 concluded to new licenses/options. Fifty-six of the licenses were nonexclusive, 35 were exclusive, and 30 were option agreements. Forty-two of the 121 agreements were with Stanford start-ups, and 23 of them involved equity (Technology \& InventionsFacts, n.d.). Reuter's top 100 world's most innovative universities 2019 survey ranks Stanford University at the top in the list (Reuters Top 100 Most Innovative Universities 2019, n.d.). Considering the framework of academic technology commercialization in other universities of the USA, there is a significant disparity in technology transfer performance as the top few universities produce a large share of revenue to the country's total technology transfer (Weis et al., 2018).

\section{Kyushu University (Japan)}

Strategies adopted by Japanese universities emphasized university-industry R\&D collaborations and creating start-ups instead of licensing of technologies. Kyushu University in Japan adopted a model termed "organization-level cooperation" from the year 2004. The approach was prioritized on a large scale with interdisciplinary research between university and industry. With the advancement in Information Technology (IT) along with the emphasis on globalization in the market, the Japanese business enterprises have shifted focus from conventional business fields to seeking profitable business fields. Under these conditions, many business enterprises are abolishing their central institutes to be replaced by collaborating with external organizations. Thus, there is growth in university-industry collaborations (UIC) leading to open innovation. The two major concerns raised by business enterprises about the universities of Japan were (1) the capability of the researchers to manage the development of their research and (2) discrepancies between the company's requirement and the researcher's motive. The IP/technology transfer activities at Kyushu University are managed by the Intellectual Property Management Center of Kyushu University (IMAQ). The strategy adopted in IMAQ is generally based on industrial demands. IMAQ in consultation with the industry partner identifies and deputes a researcher interested to work on the industrial project identified. In the due course of the project, the researcher has the freedom to exchange views and collaborate with researchers of various fields. Furthermore, Kyushu University carries out several activities such as providing technical consultation to small and medium-sized enterprises (SMEs) in the local area. This strengthens the knowledge on present needs from the local region and conducts research to fulfill the societal demands. This enables Kyushu University to suggest policies to increase investment 
for local development. In July 2005, Kyushu University collaborated with Steinbeis Foundation (StW) of Germany (business enterprise with an extensive know-how in diversified fields) and established Kyushu University-Steinbeis Japan Inc. Transfer Center (KSTC). The primary objective of KSTC is towards technological consultation of non-specific projects of joint/sponsored research and requires continued involvement of researchers from the university. This allows the university to positively respond to the requirements of local companies with a scope of building a regional innovation system (Tanigawa et al., 2011). Later in the year 2015, Academic Research and Industrial Collaboration Management Office (AiRIMaQ) was established to support academic research and collaboration. The seven groups - (i) consultation and office operation, (ii) research strategy promotion, (iii) grant support, (iv) research alliance, (v) intellectual property management, (vi) academic research promotion support, and (vii) industry-academia collaboration and community outreach support - were established under AiRIMaQ (AiRIMaQ, n.d.-a). The revenue generated from joint research projects was approximately JPN yen $2678 \mathrm{mn}$, and the amount generated from funded research projects was JPN yen $9280 \mathrm{mn}$ in the year 2019. Based on publicly available data on the AiRIMaQ website, in the year 2019, $38.3 \%$ and $31 \%$ of the patent application was generated from fields of life sciences and nanotechnology, respectively. A percentage of $25.2 \%$ of the patent applications were filed alone, and $74.8 \%$ were collaborative applications. Furthermore, the total number of the research project was 116, generating a revenue of JPN yen $603 \mathrm{mn}$ in the year 2019 (AiRIMaQ, n.d.-b). In Japan, there are successful cases of technology transfer, but the TT business is not maturing. For example, the government of Japan has been sending professional advisors on industry-university collaborative IP to universities since 2016 and intellectual property strategy designers to universities since 2019. They have also implemented measures to either reduce or exempt patent fees and examination application fees for universities. These measures are expected to improve patenting at the Japanese universities and the situation where there is a lack of expertise in intellectual property licensing strategies. The measures aim to focus on the cultivation of human resources who are responsible for the consistent practice of technology transfer from the acquisition of IP rights, financing arrangements, and development of the new markets (The Current Situation Of Technology Transfer By Universities In Japan-Intellectual Property-Japan, n.d.).

\section{Tel Aviv University (Israel)}

The universities in Israel adopt a common principle for the commercialization of academic research. The stages of commercializing are as follows. (1) The academic researcher shares the details of the potentially viable invention to Technology Transfer Company (TTC). (2) TTC assesses the potential of the invention disclosed. (3) If the invention accessed is of commercial value, TTC initiates patent filing and prepares a suitable marketing strategy to identify a potential licensee while negotiating the agreement (Research office Legislative council Secretariate, 2017). The TTC of Tel Aviv University (TAU) is Ramot. The mission of Ramot is striving to strengthen the linkage between the TAU research community and industry by securing patent protection, maximizing commercialization, encouraging the 


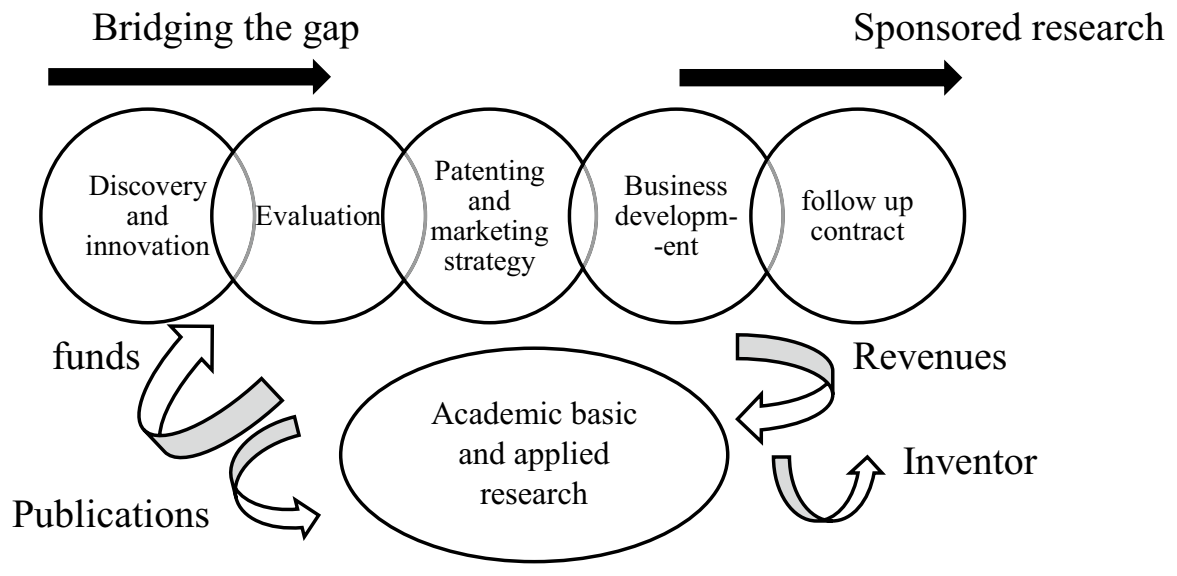

Fig. 1 Technology transfer model adopted by Tel Aviv University. Source: Technology Transfer Policy in Israel-from bottom-up to top-down? By Research Office Technical Council

transfer of emerging technologies, generating new revenue streams by licensing technologies developed, and establishing startups based on potential TAU technologies and encourage entrepreneurship at TAU (Ramot- Technology Transfer Company of Tel Aviv University, n.d.). The strategy practiced at TAU to commercialize technology is shown in Fig. 1.

Tel Aviv University applied for 256 patents between 2012 and 2017 with a success rate of $41 \%$ translating into granted patents. The commercial impact score, 31.5 , indicates the rate of basic research originating from institutions that have influenced commercial R\&D activities. Moreover, the university has established a new Center for Quantum Science and Technology in September 2019, which will bring together 20 research labs from different faculties across campus to investigate the emerging fields of quantum computing and communication (Reuters Top 100 Most Innovative Universities 2019, n.d.).

\section{Methodology}

The objectives of the study were the following:

- To understand university-industry technology transfer models in the USA, Japan, and Israel

- Propose a suitable model for fostering academic research to commercialization stage for Indian academia

We retrieved the data from published literature sources country reports and government websites. We sourced the public databases of universities from the USA, Japan, Israel, and World Intellectual Property Organization (WIPO). Qualitatively, 
Table 1 Key parameters considered for recommending a suitable model for technology transfer in Indian academia

\begin{tabular}{|c|c|}
\hline Key parameters & Scope of scrutiny \\
\hline $\begin{array}{l}\text { Comprehending the practices of university-industry } \\
\text { technology transfer (UITT) in developed nations }\end{array}$ & $\begin{array}{l}\text { - Policies governing UITT } \\
\text { - Evolution of academic commercialization } \\
\text { - Technology transfer model adapted } \\
\text { - Mechanisms encouraging academia-industry } \\
\text { collaboration } \\
\text { - Correlation between the policies and real time } \\
\text { practices of UITT }\end{array}$ \\
\hline $\begin{array}{l}\text { Case study on technology commercialization } \\
\text { aspects in universities from the USA, Japan, and } \\
\text { Israel }\end{array}$ & $\begin{array}{l}\text { - Diversity in academic commercialization strategies } \\
\text { - Advantages and limitations of UITT strategies } \\
\text { - Comprehending the revenue generated by universities } \\
\text { from TT activities }\end{array}$ \\
\hline $\begin{array}{l}\text { Interpreting the nuances of the proposed model for } \\
\text { UITT in India }\end{array}$ & $\begin{array}{l}\text { - Analyzing the models proposed based on policies } \\
\text { implemented by the government of India to encourage } \\
\text { UITT } \\
\text { - Limitations of the proposed models }\end{array}$ \\
\hline $\begin{array}{l}\text { Comprehending the barriers of UITT in Indian } \\
\text { context and recommending a suitable model }\end{array}$ & $\begin{array}{l}\text { - Based on the survey-based study conducted by } \\
\text { the authors that is published, recommending a } \\
\text { plausible model that fills the gap between the } \\
\text { stakeholders in UITT } \\
\text { - Justifying the barriers in the recommended model } \\
\text { of UITT in Indian scenario }\end{array}$ \\
\hline
\end{tabular}

we compared (a) policies on innovation and technology transfer, (b) strategies undertaken in one leading university of the countries and analyzed, and (c) the organization of TTO for successful university research commercialization. Based on the earlier models proposed for university-industry technology transfer in India, we developed a plausible model considering different variables, shown in Table 1, that are relevant to develop the proposed university-industry technology transfer model.

\section{Discussion}

\section{Analysis and Comparisons of Policy Implications on University-Industry Technology Transfer}

The Indian Patent Act 1970 laid the foundation for creative initiation and the concept of reverse engineering in the pharmaceutical sector through a structured approach. The Indian research institutions innovated over 50 pharmaceutical processes and domestic firms benefited from indigenous innovations due to the non-exclusive licenses granted by the Council of Scientific and Industrial Research (CSIR) labs. This reaffirmed the fact that innovation is encouraged by structured IP protection. The Technology Policy Statement (TPS) in 1983 was enforced with the basic objective of supporting indigenous technology and encouraging the capacity for efficient adaptation of imported technologies. TPS emphasized (1) technology development, 
(2) inventions, (3) enhancing conventional skills, (4) increasing the demand for indigenous technology, (5) fiscal incentives, and (6) establishing in-house R\&D centers. TPS encouraged a blend of indigenous and imported technology (Joseph, 2016). Later in 1986, the Research and Development Cess Act was promulgated to initiate funds for the import of technologies and to finance indigenous technologies. Simultaneously, the Technology Information Forecasting and Assessment Council (TIFAC), an autonomous body owned by the Government of India under the Department of Science and Technology, was established in 1988. The objective of TIFAC was to provide funding and encourage the development of infrastructure for commercialization (Kumar \& Jain, n.d.). In the mid-1990s, the researchers of CSIR were required to file patent applications but the policy failed to generate revenue from such patents. The majority of patents granted to CSIR during 2001-2010 were not licensed and could not generate revenue even to compensate a minimum of $5 \%$ of the cost incurred on filing the patent application by CSIR (Joseph, 2016). The policy to support academic research commercialization in India was pushed through The Protection and Utilization of Public Funded Intellectual Property Bill (PFIP) 2008. The Bill sought to provide incentives for inventions and commercialization of intellectual property from public-funded universities. The highlights of the bill were as follows. (1) The inventor must disclose the information to the research institute and within 60 days the organization must disclose the same to the government. (2) The institute should furnish the details of proposed countries intending for patent protection. (3) The inventor will be eligible for a minimum of 30\% royalties from the Public Funded Intellectual Property (PFIP). (4) Failure to intimate the government would invite penalty. However, the proposed bill never became legislation (Srivastava \& Chandra, 2012). The fear was that the industry may dictate the research and would lead to no provision for the government to steer the public-funded research (Singh \& Tare, 2010). Later in the year 2009, the National Science and Technology Entrepreneurship Development Board (NSTEDB) was established by the Ministry of Science and Technology to support the creation of entrepreneurs. The NSTEDB had encouraged the establishment of Technology Business incubators (TBI) at different universities (Srivastava \& Chandra, 2012). In 2018, All India Council of Technical Education (AICTE) encouraged a program known as AICTE Training and Learning (ATAL) Academy, to be established in all technical universities, institutes, and deemed to be universities to enhance and upgrade the technical knowledge of faculty members. The training sessions are conducted through an online portal (AICTE Training And Learning (ATAL) Academy, 2020). The Government of India under the Ministry of Human Resources and Development (MHRD), now Ministry of Education, established MHRD's Innovation Cell (MIC) to revolutionize culture of innovation and nurture students by cultivating new ideas among Higher Education Institutions (HEIs). Major initiatives undertaken by MIC include (1) Smart India Hackathon (SIH) 2019 to encourage product innovation and inculcate a problem-solving mindset (AICTE- India, 2019), (2) Institution Innovation Council (IIC) - to support the scouting and pre-incubation of ideas and develop domestic innovation ecosystem, and (3) Atal Ranking of Institutions on Innovation Achievements (ARIIA), an initiative to rank HEIs and universities in India on an index of "Innovation and Entrepreneurship Development." ARIIA encourages Indian institutions to be competitive globally 
in terms of innovation (MHRD's innovation council, Ministry of Human Resource Development, AICTE, 2019). Compared to other nations, India implemented various programs to create awareness on innovation and patenting, quite late. Though policy mechanisms were envisaged as early as 1980, the lack of implementation led to India lagging in creating a culture of innovation. Indian academia and research institutions have just realized the importance of commercializing academic research.

MAGNETON - Table 2 compares the policies implemented for encouraging university industry technology transfer in the USA, Japan, Israel, and India.

\section{Practice of Academic Technology Transfer in Indian Universities/Institutes}

The policies for patenting and innovation in Indian universities are neither robust nor systematic. In our recent study, it was found that government universities/ institutes in India with minimal industrial collaborations generate revenue through licensing, whereas private universities/organizations with more industrial collaborations fail to license their technology to an industrial partner (Ravi \& Janodia, 2021). Moreover, there is no specific model practiced in India for commercializing academic research. The strategies adopted for commercializing academic inventions are either through personal contacts of researchers or by organizing patent exhibitions. In India, the funds received by government-run universities to carry out academic research are much more compared to private universities/organizations. To understand tech transfer in perspective, we have used the Indian Institute of Technology Bombay (IITB). IITB established Industrial Research Consultancy (IRCC) in 1975 to encourage industry-focused R\&D activities. IITB filed its first patent in 1963. But the technology transfer (TT) process evolved during 2001-2011. In 2000-2001, there was no IPR policy, and the management entrusted the IPR and TT activities to technically qualified personnel. During the period, IP licensing was not much prevalent and the decisions on IP were dealt with on a case-to-case basis. The TT process between 2001 and 2006 saw a steady rise in IPR generation, interaction with industry, and other funding agencies. In 2003, IITB implemented the IPR policy for the first time, which aimed at scientific research and industry linkage and provided guidelines on ownership of IP. IRCC was strengthened during this period and emphasized channelizing IP and TT processes such as identifying the invention developed in IITB, filing relevant IP, identifying potential licensee, and royalty distribution. In 2004, with the support of the Department of Science and Technology, Government of India, IITB established an incubation center Society for Innovation and Entrepreneurship (SINE). The objective of SINE was to provide infrastructure to entrepreneurs, which included faculty, students, or alumni of the institute to establish start-ups. In 2010-2011, IITB attracted about 420 sponsored projects and 550 consultancy projects with a budget of INR 180 crores. The policy implemented this year scrutinized all master-level theses for successful IP generation. Certain marketing measures were adapted to license commercially potential IP by (a) creating a webpage for licensing technologies, (b) advertisement in media on IP/technologies for licensing, (c) fliers and booklets on licensable technology to industry, and (d) organizing TechConnect, an event in the institute for exchange of ideas and 


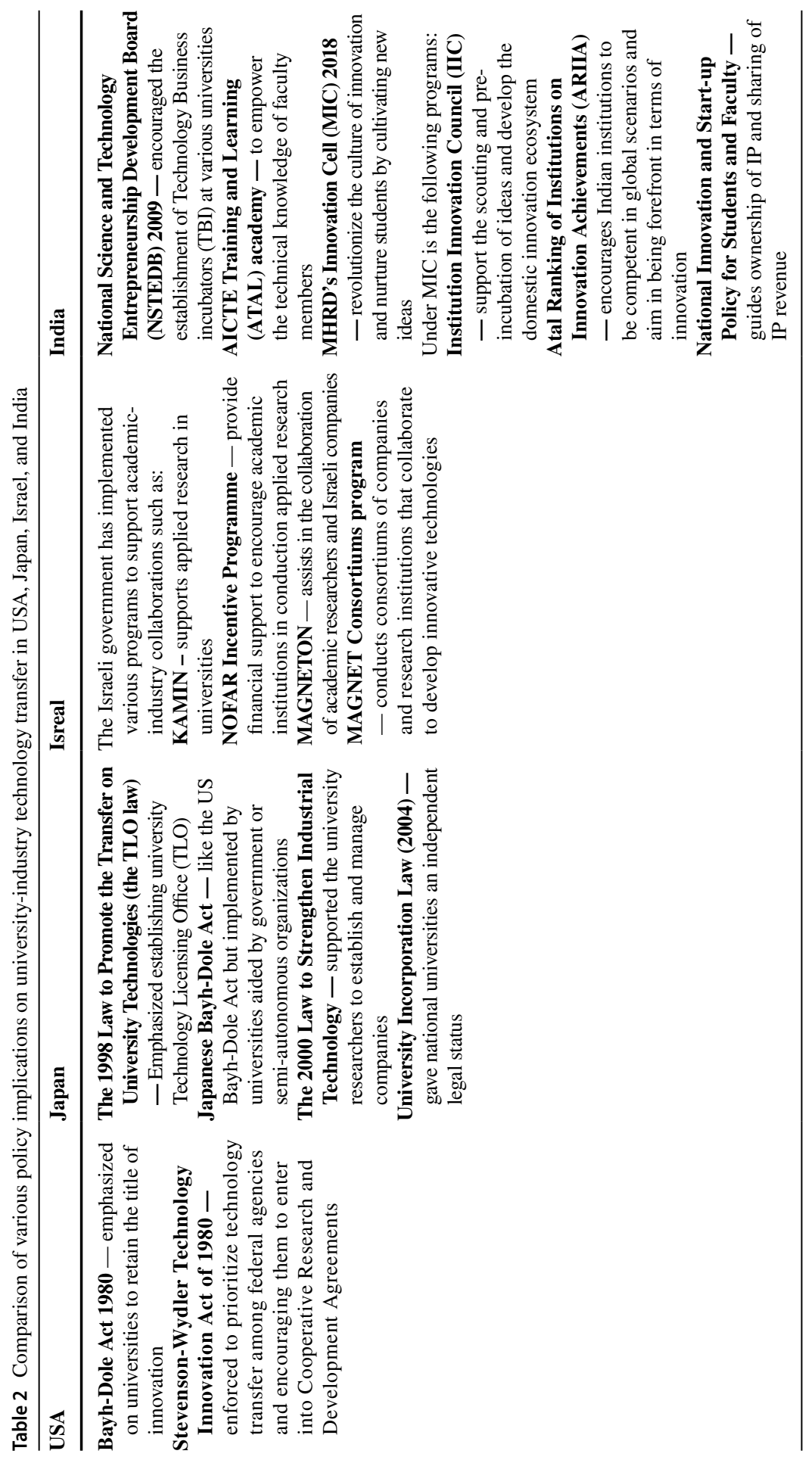


disseminate R\&D capabilities. The model of technology transfer adapted at IITB include four stages: (1) identification of the potential IP at the early stage of invention, (2) Invention Disclosure Form (IDF) submission, (3) evaluation and screening the invention disclosed by the faculty/students, and (4) efforts to position the license created for revenue. However, IITB suffered a low rate of technology commercialization (Arumugam \& Karuna, 2012; Ms \& Jain, 2010).

\section{Comparison of University Industry Technology Transfer Models in the USA, Japan, and Israel}

Considering the case studies on technology commercialization activities of universities discussed in the previous section, Table 2 compares the organization structure and offices under TTOs of Stanford (OTL), Kyushu University (AiRIMaQ), and Tel Aviv University (Ramot). Currently, approximately fifty staff members are working in OTL (OTL Staff I Office of Technology Licensing, n.d.). The number of staff working in (AiRIMaQ) of Kyushu University is about 63 members under the centers as shown in Table 3 (AiRIMaQ, n.d.-c). Ramot, the TTO office of Tel Aviv University, has 13 members to undertake the activities of IP and collaborate with industrial partners (Ramot- Technology Transfer Company of Tel Aviv University, n.d.-b).

Indeed, for Stanford, Kyushu, and Tel Aviv Universities, the establishment of Technology Transfer Office (TTO) within the university has played an instrumental role in industrial linkage. A dedicated TTO should be specialized in supportive services such as identifying potential partners, managing IP, marketing strategies, and business development. At the same time, a separate unit in TTO should update the research activities undertaken in a university (Macho-Stadler et al., 2007). Another mission of TTO as suggested in a study is to support the local economy, by either providing consultation to develop domestic companies and encourage university researchers for establishing start-ups or creating a job for the locals (Warrena et al., 2008).

There are very few models proposed in the literature for supporting academic research commercialization in India. One such model was proposed by Rath et al. The model emphasized the functioning of the technology transfer office (TTO). The study recommended that the TTOs must (i) compose guidelines for collaboration and patenting activities, (ii) abstract venture capitalists and fiscal incentives, and (iii) enlist a detailed structure on research outcomes (Rath et al., 2014). Another model was proposed by Srivastava et al. in the year 2012. The model focused on the process of technology transfer with a primary objective on licensing agreements. Furthermore, the paper discusses the nuances of licensing concerning technical feasibility, commercial factors, discount factors in sublicensing, and finally the termination policy of licensing (Srivastava \& Chandra, 2012). Another study proposed two models based on the Indian academic context. Type 1 was based on concept of technology push that is research based and the outcome leading to publications and patenting. Type 2 was based on a business pull process that had an entrepreneurial agenda and the outcome leading to venturing (Kuriakose, 2016). The major shortcomings of the models are (a) lack of central policy or guideline for technology 


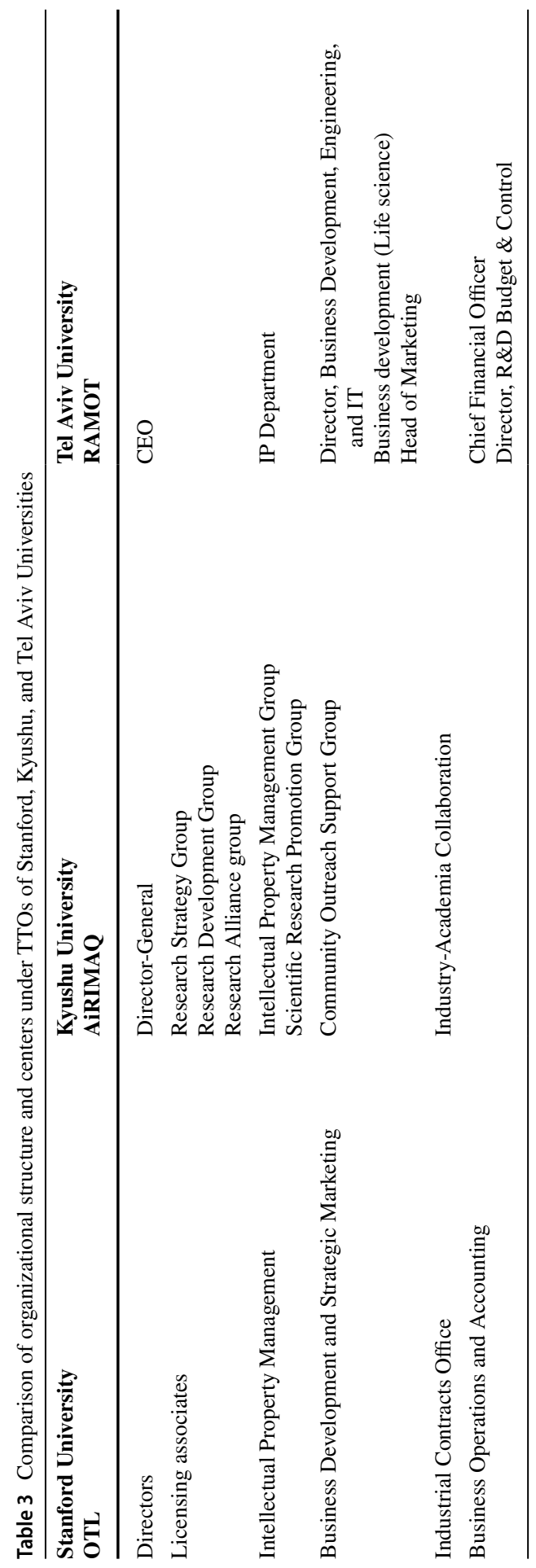


transfer, (b) lack of a dedicated mechanism to attract the potential licensee, (c) lack of structure to promote collaborative research between faculty and industry, and (d) inadequate mechanisms to share the profits from commercialization with inventors. The model proposed in this paper considers the importance of all stakeholders involved in successful technology transfer that include the government, industry, and academia. Moreover, the recommended model emphasizes on assessing the technology readiness level (TRL), which is essential for a successful strategy for technology licensing/transfer/commercialization.

\section{Conceptual Model Recommended for University-Industry Tech Commercialization in India}

In order, to improve university-industry technology transfer in India, we propose a conceptual model that is suitable to the Indian context. The translation of academic research into commercial products leading to economic growth is much needed. Most universities in India have an off-late established Technology Transfer Office (TTO) as mandated by the Government of India (GOI) through various ranking and accreditation processes. In India, research funding received by public-funded universities is high compared to that of private universities/organizations (Ravi \& Janodia, 2021). Currently, BIRAC, Dept of Biotechnology, funds a proposal that has a commercial value of research in academia having an industrial partner. Drawing from the Triple Helix model of UITT, the Govt must be the interface to encourage UITT in various aspects as shown in Fig. 2 (Ranga \& Etzkowitz, 2013). The primary role of the Government of India as proposed in our model is to create central repositories exhibiting the research outcomes from universities/institutes/research centers/organizations via a common portal accessible to both industry and university. The initiative can create an opportunity to collaborate either between universities (public and

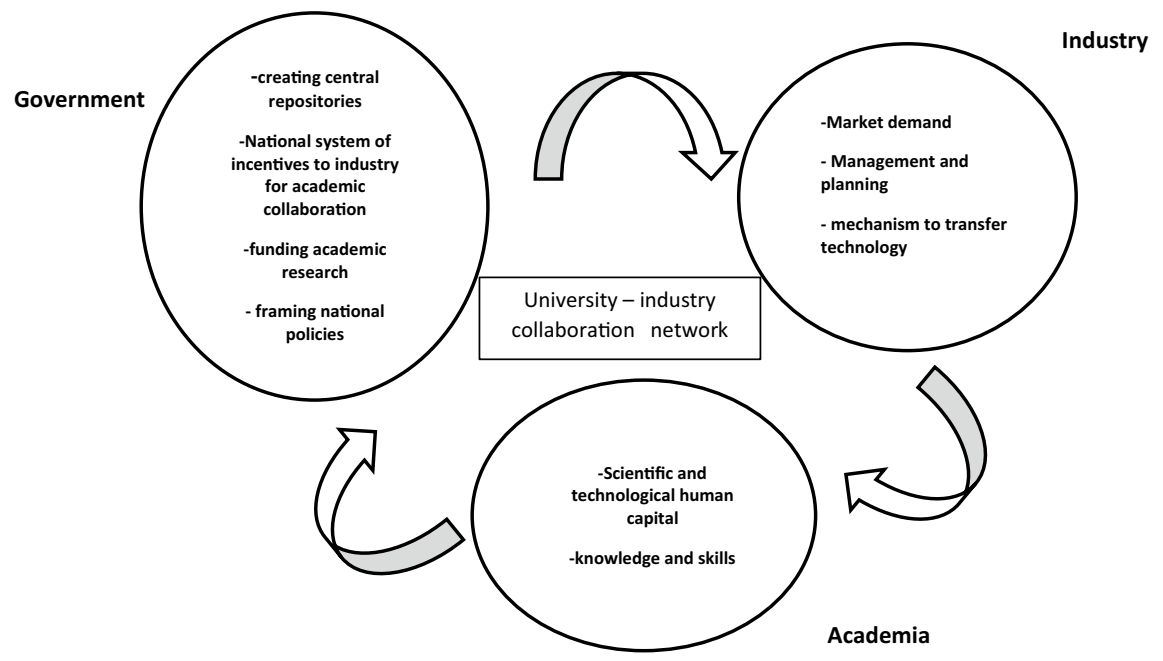

Fig. 2 Relationship between university-industry and government 
private) and between academia-industry based on the agreeable research interest of both organizations. The other advantages to the proposed model are the following: (a) potential licensors would have fewer options to visit and establish relationships; (b) combining the resources of licensing will aid value addition for inventions; and (c) it enhances greater contact with the marketplace, and thus the research carried out in academia will be in coherence with societal demands. The other fundamental contribution of GOI to the universities is to frame policies enhancing UITT and implement schemes to support various areas of research. Moreover, the model suggests a consortium of industrial partners and industrial involvement in academic research at an early stage.

Further, the government can encourage commercialization by providing fiscal incentives or tax holidays for products commercialized that have an academic origin. This enables a win-win situation for universities/institutes and industries. Furthermore, the research products marketed from such collaborations can benefit society with better commodities to meet the market demand. The conceptual model proposed by Mondragón et al. in the year 2013 for public universities in Mexico addressed the following barriers - (a) identification of the idiosyncratic factors in Mexican public universities that affect their technology transfer performance, (b) creation of a strategic partnership among institutions through research network, (c) the research from universities which is not leveraged commercially, and (d) lack of ecosystem for technological commercialization. The model also emphasized the importance of policies by the government that needs to be tailored for regional development rather than a one-size-fits-all approach (Necoechea-Mondragón et al., 2013). Another model proposed by Bradley et al. (2015) emphasized the platform to connect academia and industry through the internet employing collaborative organization. Such organizations aim for matching the innovators with potential collaborators and supply resources to develop the product (Bradley et al., 2015).

Looking into various models proposed globally and based on our previous study, (Ravi \& Janodia, 2021), we propose a model as shown in Fig. 3.

The policies to encourage UITT and a central repository to attract partners to commercialize available IP and technology are the immediate necessity for India. The model proposes various stages of UITT. (1) The research outcome can be either one or a combination of (a) publications, (b) patent through IP, and (c) technology ready for development. (2) Technology assessment — for any research institute, applying legal instruments to guarantee ownership and exclusive exploitation is essential. The university can either apply for a patent or assess the potential of technology through Technology Readiness Level (TRL) - technology to be transferred requires assessment for its potential before acquisition at whatever stage of development. This demands the buyer to seek legal protection of the technology and to take corrective measures if necessary or possible. The criteria for assessment of technology include diversifying/mitigating risk and resources to enhance the development of concerning technology and bring it to a stage where it can be licensed or sold. (3) Market assessment - the major area of concern in India is that the university research is not in line with market demand. The market assessment also includes the valuation of technologies and the economic analysis that is based on market research (including the demand for technology and identification of potential licensees). The market assessment involves considering 


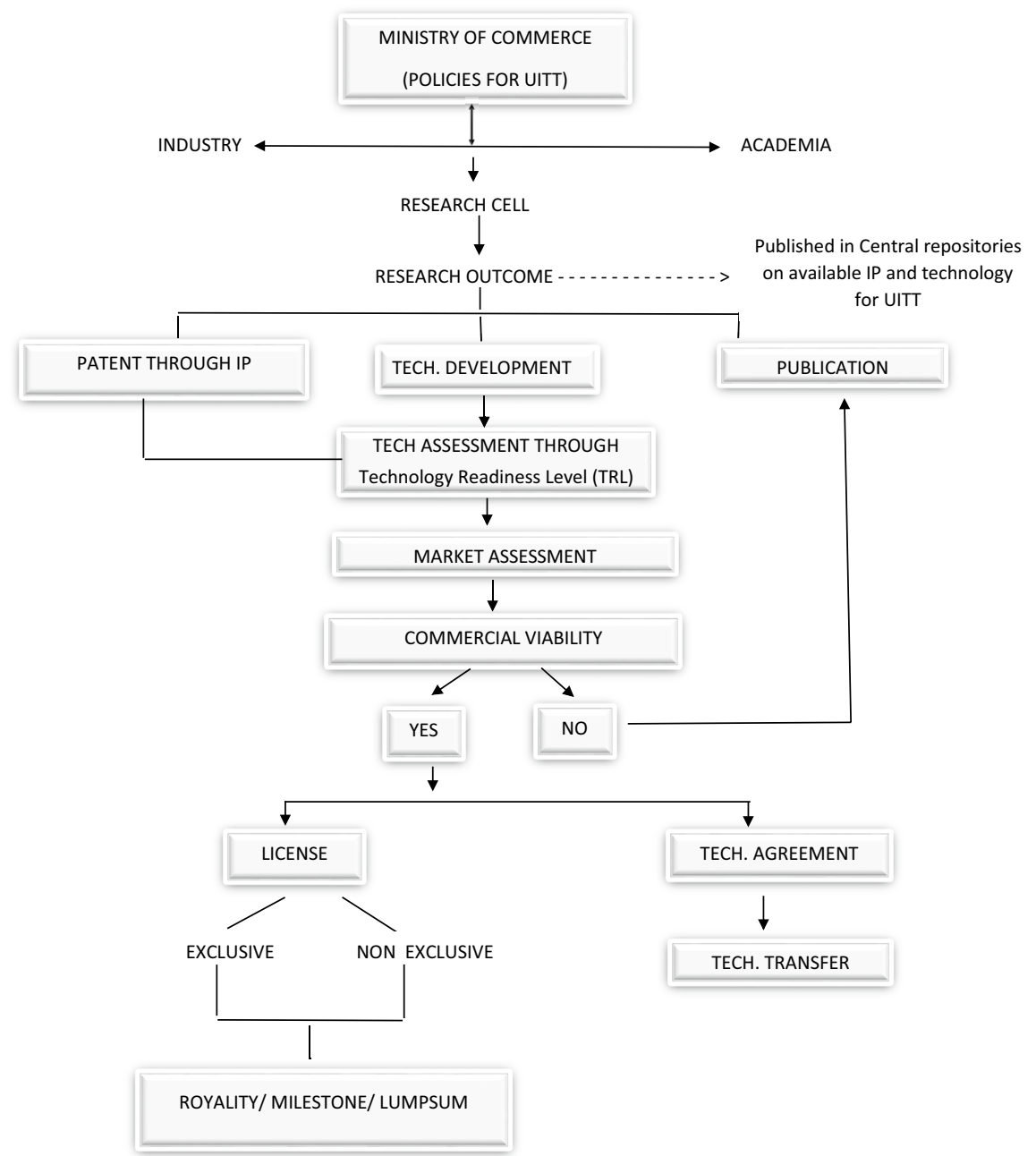

Fig. 3 A proposed alternate model for UITT in an Indian scenario

various factors such as (i) size of the market targeted, (ii) business model to support the desired market, (iii) barriers to enter the market, (iv) gross margin, (v) number of competitors, (vi) mechanism for penetration of the product into the market, and (vii) analysis of the commercial potential of the licensee (Condom et al., 2008). (4) Commercial viability - determination of commercial potential of a technology is a prerequisite for framing successful commercialization strategies. Early recognition of the commercial potential of the technology concerned represents the use of resources efficiently and aids in developing the technology in the future. The viability of the technology not only is based on technical aspects but also depends on the financial, legal, regulatory, market, and numerous other factors. The early identification of commercial potential for new technology is based on four fundamental objectives. (i) Validation of 
commercialization - establishes that the technology has the overall business potential and justify commercialization and broadening of commercialization in the future. (ii) Realistic assessment of the utility of technology — aims at connecting the real-world needs against the attributes of technology. (iii) Accurately targeting commercialization - research organizations can target a specific market, industries which could utilize the technology potentially in a cost-effective manner. (iv) Commercial action can be initiated by either advertising or promoting by various other mechanisms (Bandarian, 2007). If the new technology is satisfying all the criteria above, it can be either licensed if the patent is granted or can be transferred to potential licensee based on terms agreed upon. The license granted may be exclusive or non-exclusive based on the technology, and payment options can be either royalty, milestone, or agreed mechanism of benefit sharing. The cost includes the overall costs of technology development to be licensed. It also includes the cost of protecting IP, the salary of the staff involved. This involves the agreements based on the evolution of the technology concerned where the cost system may allow a downpayment on the transfer of technology complimenting future payments.

\section{Conclusion}

This paper argues that the current scenario for university-industry technology transfer in India is evolving compared to other developed countries. This research contributes to the successful practices adopted by the universities in the USA, Japan, and Israel. The strategies adopted by the universities can be adapted to meet Indian requirements for enhancing university-industry technology transfer. A few models for the Indian context are proposed earlier, which has limitations, whereas our proposed model attempts to address some of the lacunae by assessing the technology through TRL and also provides a more practical approach to be implemented for successful outcome of university-industry technology transfer. Further, there has to be a strong industry connection by academia from the beginning of research project that would help a few projects translate into successful licensing/tech transfer. The government as a facilitator to enhance these collaborative activities plays a vital role through creating facilitating mechanism and development of framework. Based on the practice of technology transfer in developed nations, the paper recommends a conceptual model adapted for university-industry technology transfer in the Indian context.

Funding Open access funding provided by Manipal Academy of Higher Education, Manipal.

Open Access This article is licensed under a Creative Commons Attribution 4.0 International License, which permits use, sharing, adaptation, distribution and reproduction in any medium or format, as long as you give appropriate credit to the original author(s) and the source, provide a link to the Creative Commons licence, and indicate if changes were made. The images or other third party material in this article are included in the article's Creative Commons licence, unless indicated otherwise in a credit line to the material. If material is not included in the article's Creative Commons licence and your intended use is not permitted by statutory regulation or exceeds the permitted use, you will need to obtain permission 
directly from the copyright holder. To view a copy of this licence, visit http://creativecommons.org/ licenses/by/4.0/.

\section{References}

AICTE - India. (2019). Smart - India Hackaton. https://www.aicte-india.org/Initiatives/smart-india-hackathon AICTE Training And Learning (ATAL) Academy. (2020). Government of India. 410917. https://www. aicte-india.org/sites/default/files/ATAL/atal\%20vision\%20mission.pdf

AiRIMaQ. (n.d.-a). Retrieved March 1, 2021, from https://airimaq.kyushu-u.ac.jp/en/so/history.php

AiRIMaQ. (n.d.-b). Retrieved March 1, 2021, from https://airimaq.kyushu-u.ac.jp/en/tj/results.php

AiRIMaQ. (n.d.-c). Retrieved April 4, 2021, from https://airimaq.kyushu-u.ac.jp/en/so/staff.php

Arumugam, V., \& Karuna, J. (2012). Technology Transfer from Higher Technical Institutions to the Industry in India-A Case study of IIT Bombay. Journal of Intellectual Property Rights, 17(March), 141-151. Retrieved from http://nopr.niscair.res.in/bitstream/123456789/13719/3/JIPR17(2)141151.pdf?utm_source $=$ The_Journal_Database \&trk=right_banner\&id=1406799061 \& ref= 34ed98bae7d800f3fcbbc32a8abc5eac

Axanova, L. (2012). U.S. Academic technology transfer models: Traditional, experimental And hypothetical. Nouvelles-Journal of the Licensing Executives Society, 47(2), 125-137.

Bandarian, R. (2007). Measuring commercial potential of a new technology at the early stage of development with fuzzy logic. Journal of Technology Management \& Innovation, 2(4), 73-85.

Berneman, L. P., \& Denis, K. A. (1998). Evolution of academic- industry technology transfer in the USA, (August).

Bradley, S. R., Hayter, C. S., Link, A. N., Bradley, S. R., Hayter, C. S., \& Link, A. N. (2015). Concise guide to entrepreneurship, technology and innovation. Concise Guide to Entrepreneurship, Technology and Innovation, (June). https://doi.org/10.4337/9781783474202

Collins, S., \& Wakoh, H. (2000). Universities and technology transfer in Japan: Recent reforms in historical perspective. Journal of Technology Transfer, 25(2), 213-222. https://doi.org/10.1023/A:1007884925676

Condom, P., Ignasi, C., Alberto, O., Roger, P., Jose Maria, E., \& Villà. (2008). Key issues of technology transfer from public research centres to businesses.

Federal Technology Transfer Act and Related Legislation I Advancing the Federal Technology Transfer Act (FTTA) I US EPA. (n.d.). Retrieved March 1, 2021, from https://www.epa.gov/ftta/federal-technologytransfer-act-and-related-legislation

Joseph, R. K. (2016). Who will Gain from the National IPR policy, (July 2016). Retreived April 4, 2021, from http://isid.org.in/pdf/ISIDpb01.pdf

King, D. R., \& Nowack, M. L. (2003). The Impact of Government Policy on Technology Transfer : An Aircraft Industry Case Study, 20, 303-318. https://doi.org/10.1016/j.jengtecman.2003.08.007

Kneller, R. (2011). Invention management in japanese universities and its implications for innovation: Insights from the university of tokyo. Academic Entrepreneurship in Asia: THe Role and Impact of Universities in National Innovation Systems, 69-85. https://doi.org/10.4337/9780857938008.00007

Kumar, V., \& Jain, P. K. (n.d.). Unknown - Unknown - Kumar, Jain - 2002 - Commercializing new technologies in India a perspective on policy initiatives.pdf.

Kuriakose, F. (2016). Exploring university-industry technology transfer in India: Two models. SSRN Electronic Journal, (September), 1-20. https://doi.org/10.2139/ssrn.2838103

Lamm, M. (2018). Technology transfer: United States policy and laws. Retrieved April 3, 2021, from https://www.unece.org/fileadmin/DAM/ceci/ppt_presentations/2010/eed/lamm.pdf

Macho-Stadler, I., Pérez-Castrillo, D., \& Veugelers, R. (2007). Licensing of university inventions: The role of a technology transfer office. International Journal of Industrial Organization, 25(3), 483510. https://doi.org/10.1016/j.ijindorg.2006.06.001

Messer-Yaron, H. (2014). Technology transfer policy in Israel. Retrieved March 21, 2021 from https://ec. europa.eu/assets/jrc/events/20140120-tto-circle/jrc-20140120-tto-circle-messer.pdf

MHRD's innovation council, Ministry of Human Resource Development, AICTE. (2019). National innovation and startup policy 2019 for students and faculty. Retrieved April 4, 2021, from https://mic.gov.in/assets/ doc/startup_policy_2019.pdf

Ms, P., \& Jain, K. (2010). Utilising patent portfolios for effective technology transfer A case learning in IIT Bombay. 31-37. Retreived April 4, 2021, from, http://www.techmonitor.net/tm/images/4/40/10nov_dec_sf4.pdf 
Nandagopal, M. (2013). Commercializing technologies from universities and research institutes in India: Some insights from the US experience. Current Science, 104(2), 183-189.

Necoechea-Mondragón, H., Pineda-Domínguez, D., \& Soto-Flores, R. (2013). A conceptual model of technology transfer for public universities in Mexico. Journal of Technology Management and Innovation, 8(4), 24-35. https://doi.org/10.4067/s0718-27242013000500002

Office of Licensing Technology, S. (2012). Stanford Inventor's Guide, 1-44. Retrieved February 3, 2021, from https://web.stanford.edu/group/OTL/documents/OTLinventorsguide.pdf

OTL Staff I Office of Technology Licensing. (n.d.). Retrieved April 1, 2021, from https://otl.stanford.edu/ about/otl-staff

Page, N. (2008). Chapter 17.13: The making of a licensing legend: Stanford University's Office of Technology Licensing. IpHandbook of Best Practices, 1719-1728. Retrieved February 3, 2021, from http:// www.iphandbook.org/handbook/chPDFs/ch17/ipHandbook-Ch1713PageOTLatStanfordUniversity.pdf

Ramot- Technology Transfer Company of Tel Aviv University. (n.d.). Retrieved March 6, 2021, from https://ramot.org/about-ramot

Ramot- Technology Transfer Company of Tel Aviv University. (n.d.-b). Retrieved April 4, 2021, from https://ramot.org/about-ramot/team

Ranga, M., \& Etzkowitz, H. (2013). Triple Helix Systems: An Analytical Framework for Innovation Policy and Practice in the Knowledge Society. Industry and Higher Education, 27. https://doi.org/10. 5367/ihe.2013.0165

Rath, S., Nathani, A., Patel, D., Kulkarni, P., \& Gota, V. (2014). Status of technology transfer in India The much needed Magic Remedy. Current Science, 106(8), 1058-1060. https://doi.org/10.18520/cs/ v106/i8/1058-1060

Ravi, R., \& Janodia, M. D. (2020). Academia- industry technology transfer - A detailed study on indian scenario at global platform. Research Journal of Pharmacy and Technology, 13(10), 4981. https:// doi.org/10.5958/0974-360x.2020.00873.2

Ravi, R., \& Janodia, M. D. (2021). Factors affecting technology transfer and commercialization of university research in India: A cross-sectional study. Journal of the Knowledge Economy, (0123456789). https://doi.org/10.1007/s13132-021-00747-4

Research office Legislative council Secretariate, (2017). Innovation and tehnology industry in Israel. Retrieved March 6, 2021, from https://www.legco.gov.hk/research-publications/english/1617fsc23innovation-and-technology-industry-in-israel-20170712-e.pdf

Reuters Top 100 Most Innovative Universities 2019. (n.d.). Retrieved September 17, 2021, from https://graph ics.reuters.com/AMERS-REUTERSRANKING-INNOVATIVE-UNIVERSITIES/0100B2JP1W1/index. html ?initialWidth=940\&childId=targetdiv\&parentTitle=TheWorld'sMostInnovativeUniversities2019\& parentUrl=https\%3A\%2F\%2Fwww.reuters.com\%2Finnovative-universities-2019\#results30100000003474

Singh, R., \& Tare, S. (2010). India's emerging technology commercialization policy: Lessons from the American model. Journal of Emerging Knowledge on Emerging Markets, 2(1), 1-30. https://doi.org/10.7885/1946651x. 1025

Srivastava, P., \& Chandra, S. (2012). Technology commercialization: Indian university perspective. Journal of Technology Management and Innovation, 7(4), 121-131. https://doi.org/10.4067/S071827242012000400010

Takenaka, T. (2005). Technology licensing and university research in Japan. International Journal of Intellectual Property -Law, Economy and Management, 1(1), 27-36. https://doi.org/10.2321/ijip.1.27

Tanigawa, T., Sasaki, H., \& Takata, M. (2011). The role and impact of universities in national and regional innovation systems: Kyushu University's experience. Academic Entrepreneurship in Asia: The Role and Impact of Universities in National Innovation Systems. https://doi.org/10.4337/9780857938008.00006

Technology \& Inventions - Facts. (n.d.). Retrieved March 2, 2021, from https://facts.stanford.edu/research/ innovation/

Technology Transfer in Countries in Transition: Policy and Recommendations Division for Certain Countries in Europe and Asia Technology Transfer in Countries in Transition: Policy and Recommendations. (n.d.). Retrieved March 21, 2021, from https://www.wipo.int/edocs/pubdocs/en/wipo_ pub_transition_2_b.pdf

Technology Transfer Licensing Survery I AUTM. (n.d.). Retrieved September 16, 2021, from https://autm. net/surveys-and-tools/surveys/licensing-survey/2020-licensing-survey/2020-survey-for-industry?gclid= Cj0KCQjw1 ouKBhC5ARIsAHXNMI8pvGAkL2iMt27GBXv-f3dd6Ld1eiUWy8cQx73I2WXAl ILZTuqBolkaAjhZEALw_wcB 
The Current Situation Of Technology Transfer By Universities In Japan - Intellectual Property - Japan. (n.d.). Retrieved September 17, 2021, from https://www.mondaq.com/patent/1018328/the-currentsituation-of-technology-transfer-by-universities-in-japan

Wain, M., Nielsen, K., Potau, X., \& Simmonds, P. (n.d.). Review of International Knowledge Transfer Policy and Investment A report to Knowledge Transfer Ireland Review of International Knowledge Transfer Policy and Investment. Retrieved March 10, 2021, from https://www.knowledgetransferireland. com/Reports-Publications/Review-of-International-Knowledge-Transfer-Policy-and-Investment.pdf

Warrena, A., Hankeb, R., \& Trotzerc, D. (2008). Models for university technology transfer: Resolving conflicts between mission and methods and the dependency on geographic location. Cambridge Journal of Regions, Economy and Society, 1(2), 219-232. https://doi.org/10.1093/cjres/rsm009

Weis, J., Bashyam, A., Ekchian, G. J., Paisner, K., Vanderford, N. L., Deak, K. I., ... Paschall, C. (2018). Evaluating disparities in the U.S. technology transfer ecosystem to improve bench to business translation. [version 1; peer review: 3 approved, 1 approved with reservations]. 7. https://doi.org/10. 12688/f1000research.14210.1

Wonglimpiyarat, J. (2016). Government policies towards Israel's high-tech powerhouse. Technovation, 52-53, 18-27. https://doi.org/10.1016/j.technovation.2016.02.001

Publisher's Note Springer Nature remains neutral with regard to jurisdictional claims in published maps and institutional affiliations. 